\title{
A new proximal femoral nail antirotation design: Is it effective in preventing varus collapse and cut-out?
}

\author{
Kerim Öner, $\mathrm{MD}^{1}{ }^{1}$, Serhat Durusoy, $\mathrm{MD}^{1} \mathbb{1}$, Alaettin Özer, $\mathrm{PhD}^{2} \mathbb{D}$ \\ ${ }^{1}$ Department of Orthopedics and Traumatology, Yozgat Bozok University Faculty of Medicine, Yozgat, Turkey \\ ${ }^{2}$ Department of Mechanical Engineering, Yozgat Bozok University, Faculty of Engineering, Yozgat, Turkey
}

Intertrochanteric femoral fractures (ITFFs) are among the most common fractures in the elderly osteoporotic population. ${ }^{[1]}$ The prevalence of ITFFs has increased with the recent increase in life expectancy. ${ }^{[2]}$ Of these fractures, $35-40 \%$ are unstable. ${ }^{[3,4]}$ Hip fractures are associated with increased mortality, particularly in elderly patients. They are treated with a surgical approach other than in rare cases where surgery has a very high mortality risk ${ }^{[5]}$ Mortality and morbidity rates are significantly higher in elderly patients that require ITFF revision surgery. Therefore, precise reduction, a properly executed fixation, and early mobilization are vital. ${ }^{[6]}$

Intertrochanteric femoral fractures can be treated with an intramedullary or extramedullary treatment approach. Available studies report favorable results for intramedullary nailing in the treatment of intertrochanteric fractures. ${ }^{[7]}$ The complications that can be seen in patients that have undergone

Received: April 02, 2020

Accepted: April 30, 2020

Published online: June 24, 2020

Correspondence: Kerim Öner, MD. Yozgat Bozok Üniversitesi Tıp Fakültesi Eğitim ve Araştırma Hastanesi, Ortopedi ve Travmatoloji Kliniği, 66100 Yozgat, Türkiye.

E-mail: dr.kerimoner@hotmail.com

Doi: $10.5606 /$ ehc. 2020.75113

Citation: Öner K, Durusoy S, Özer A. A new proximal femoral nail antirotation design: Is it effective in preventing varus collapse and cut-out?. Jt Dis Relat Surg 2020;31(3):426-431.

(C2020 All right reserved by the Turkish Joint Diseases Foundation

This is an open access article under the terms of the Creative Commons Attribution-NonCommercial License, which permits use, distribution and reproduction in any medium, provided the original work is properly cited and is not used for commercial purposes (http://creativecommons.org/licenses/by-nc/4.0/).

\section{ABSTRACT}

Objectives: This study aims to compare the mechanical features of the existing proximal femoral nail antirotation (PFNA) system and the new PFNA system that we designed using three-dimensional (3D) finite element analysis.

Materials and methods: This experimental study was conducted between 2019 and 2020. We constructed two femur models with Arbeitsgemeinschaft für Osteosynthesefragen (AO) type A1 fractures using $3 \mathrm{D}$ computed tomography scans. The new and standard PFNA designs were inserted into the femur models and subsequently transferred to the program. We investigated the distribution of stress on the tip of the lag screw, the calcar region, lag screw-nail junction, and the additional screw inserted through the greater trochanter (only present in the new PFNA design) using 3D finite element analysis.

Results: When the von Mises stress distributions in our models were examined, the maximum stress at the lag screw-nail junction was $18 \mathrm{mpa}$ in the new design PFNA, while it was $20 \mathrm{mpa}$ in the classic PFNA model. The maximum stress at the junction of the additional screw that had greater trochanter inlet with the nail was found as $42.5 \mathrm{mpa}$. The maximum stress on the calcar region was found to be $10 \mathrm{mpa}$ at the new design PFNA, while it was $13 \mathrm{mpa}$ with $30 \%$ increase in the classic PFNA. The stress on the tip of the lag screw was found to be $49 \mathrm{mpa}$ in the classic PFNA design, while in the new design PFNA it was found as $28 \mathrm{mpa}$ with a decrease of more than $40 \%$.

Conclusion: As per our findings, the new PFNA design leads to reduced stress on the lag screw-nail junction, the calcar region, and the tip of the lag screw.

Keywords: Intertrochanteric femoral fractures, new design proximal femoral nail antirotation, three-dimensional finite element analysis.

surgery include varus collapse, shortening of the femoral neck, implant failure, and cut-out. ${ }^{[8]}$ Implant design is crucial in reducing complication rates. Studies have shown that the technical and biomechanical properties of implants impact implant failure. ${ }^{[9]}$ The helical neck blade has the advantages of fixation stability, anti-rotation, and anti-varus collapse. ${ }^{[10]}$ Biomechanical studies showed that the 
new generation of Gamma nail appeared to be stronger and to reduce the risk of lag screw cuttingout. ${ }^{[11]}$

Despite many studies, there is currently no consensus on the ideal implant design that will provide optimum stability. ${ }^{[12]}$ In this study, we aimed to compare the mechanical features of the existing proximal femoral nail antirotation (PFNA) system and the new PFNA system that we designed using threedimensional (3D) finite element analysis.

\section{MATERIALS AND METHODS}

This experimental study was conducted at Yozgat Bozok University Faculty of Medicine, between 2019 and 2020. We developed a femur model using data obtained from 3D computed tomography scans. We created an Arbeitsgemeinschaft für Osteosynthesefragen (AO) type A1 fracture extending from the greater to the lesser trochanter on two femur models. ${ }^{[13]}$ We used a PFNA implant (implant length, $200 \mathrm{~mm}$; implant diameter, $11 \mathrm{~mm}$; lag screw length, $85 \mathrm{~mm}$ ). In the new PFNA design, we included an additional screw that was inserted through the greater trochanter making a 45-degree angle with the nail and connected to the nail with a thread system. The additional screw had a diameter of $5 \mathrm{~mm}$ and a blunt end, and passed through the nail and lag screw and rested on the inner surface of the calcar (Figure 1a). The lag screw was designed with an oblique $6-\mathrm{mm}$ slot for the passage of the additional screw so as to allow easy application without causing mechanical weakness (Figure 1b). The new and standard PFNA models were transferred to the ANSYS Workbench program (Ansys Inc., Canonsburg, Pennsylvania, USA). The two models were compared under mechanical loading using the 3D finite element method. We evaluated maximum stress levels at the tip of the lag screws, at the lag screw-nail junction, in the additional screw that was inserted through the greater trochanter, and in the calcar region.

Linear elastic and isotropic material model was assumed for all bone and other metal alloys. Material properties $\mathrm{E}=16.8 \mathrm{GPa}, v=0.3 ; \mathrm{E}=110 \mathrm{GPa}, v=0.33$ were used for simulations as cortical bone and titanium parts such as PFNA and lag screw. ${ }^{[14]}$

Bone to bone contact interface, such as fracture interface, was considered as completely broken, frictional sliding contact and 0.2 was taken as friction coefficient. ${ }^{[14]}$ Contact interface with PFNA and lag screw was assumed as bonded without sliding in order to better simulate real condition. Also, lag screw was connected to femoral head as bonded without sliding. The other contact interfaces of bone-to-titanium and titanium-to-titanium parts were taken as frictional and bonded according to real conditions. Friction coefficient for bone-to-titanium interfaces was taken as $0.46 .^{[15]}$ Every model was fixed at the bottom of the femur model. Forces were applied as constraints and static solutions were realized.

The femur models were subjected to forces from three directions that are commonly used in the literature. ${ }^{[14]}$ The configurations of the simulated forces were as follows: 2460 newtons from the acetabular fossa to the femoral head ( 23 degrees in
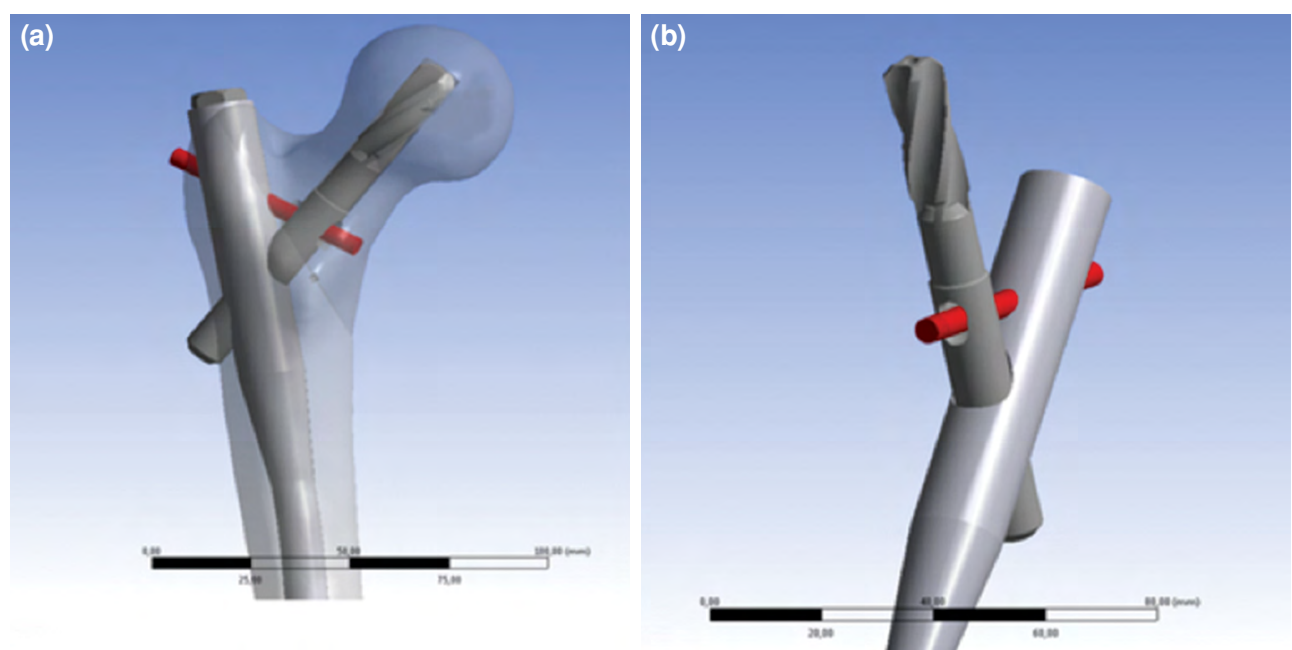

FIGURE 1. (a) Insertion of additional screw through greater trochanter, nail, and lag screw. (b) New proximal femoral nail antirotation design. 


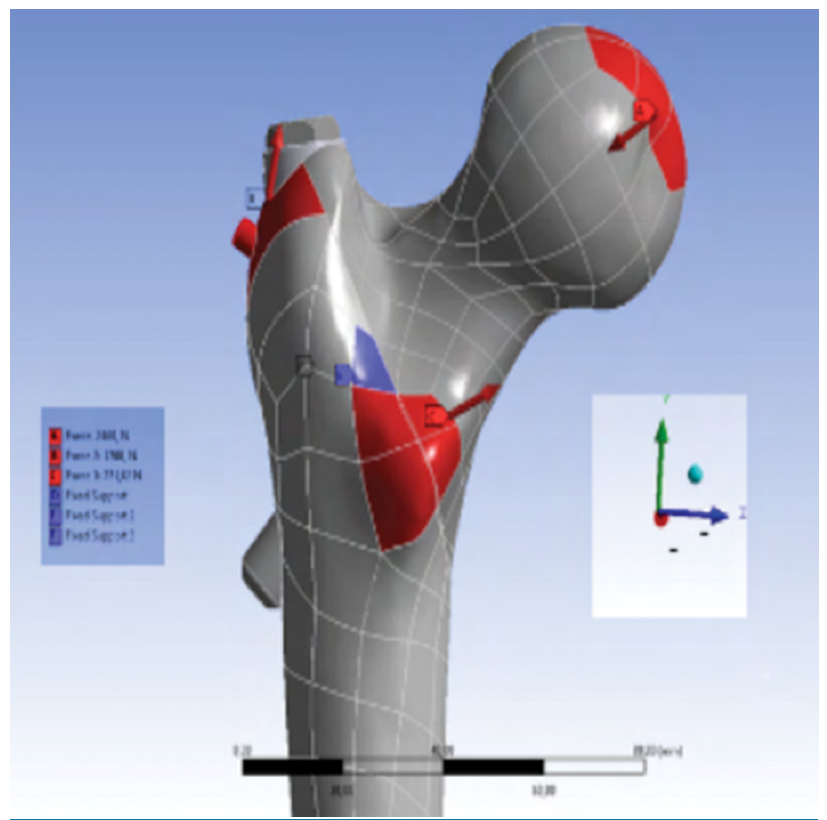

FIGURE 2. Demonstration of forces applied to models (2460 newtons to femoral head, 1700 newtons to greater trochanter, 771 newtons to lesser trochanter). the frontal plane, 68 degrees in the sagittal plane), 1700 newtons from the abductor muscles to the greater trochanter (24 degrees in the frontal plane, 15 degrees in the sagittal plane), and 771 newtons from the iliopsoas muscle to the lesser trochanter (41 degrees in the frontal plane, 26 degrees in the sagittal plane) (Figure 2). ${ }^{[14]}$

\section{RESULTS}

When the von Mises stress distributions of the two designs we modeled at three different points (lag screw tip, lag screw-nail junction and calcar region) were examined, the maximum stress at the lag screw-nail junction was $18 \mathrm{mpa}$ at the new design PFNA and $20 \mathrm{mpa}$ at the standard PFNA model. Only the maximum stress at the junction of the additional screw that had greater trochanter inlet in the new design with the nail was found as $42.5 \mathrm{mpa}$. The maximum stress on the calcar region was found to be $10 \mathrm{mpa}$ at the new design PFNA, while it was 13 mpa with $30 \%$ increase in the standard PFNA (Figure 3a, b). The efficiency of our additional screw
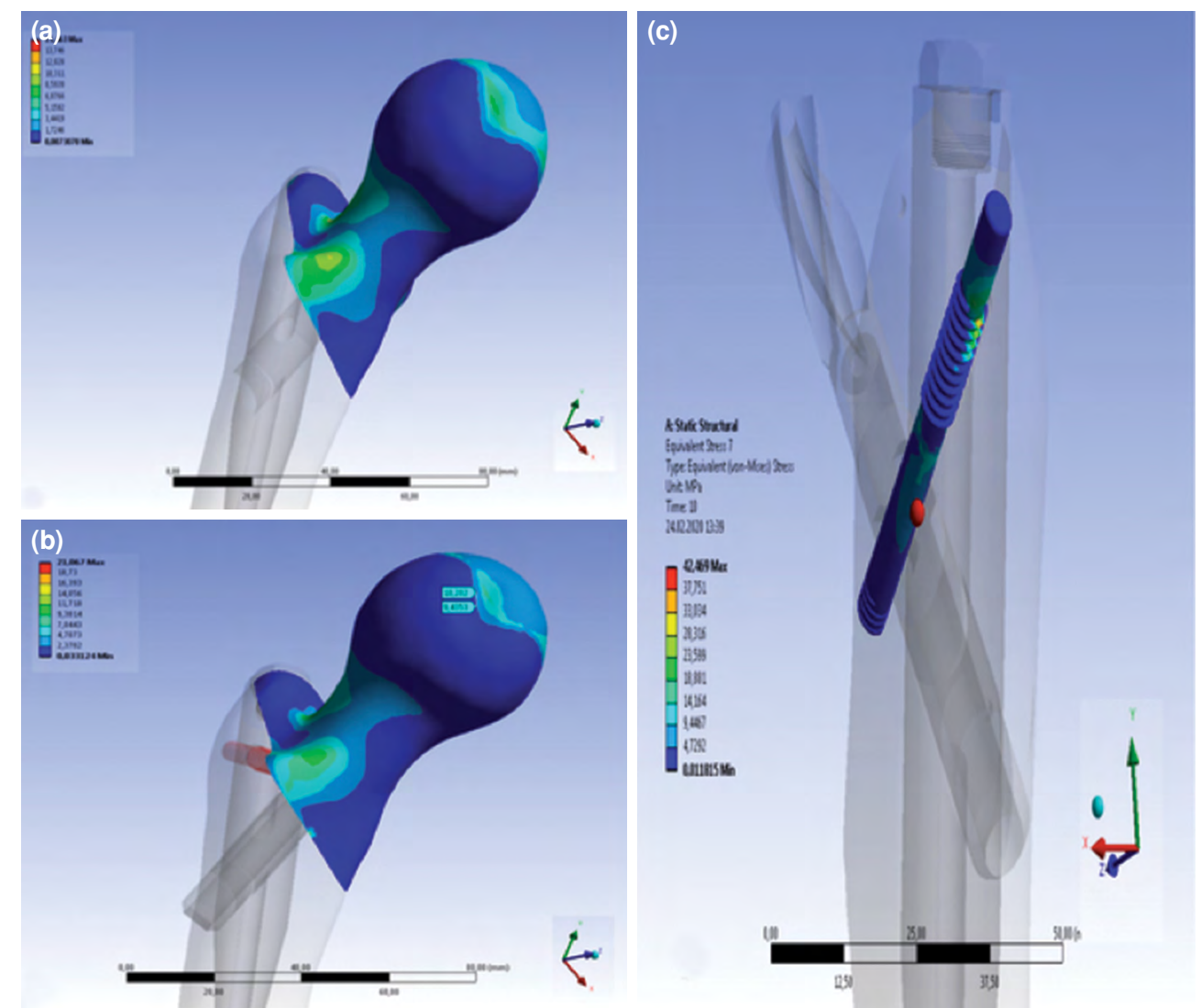

FIGURE 3. (a, b) Demonstration of stress on calcar region. (c) Demonstration of stress on screw inserted through greater trochanter. 

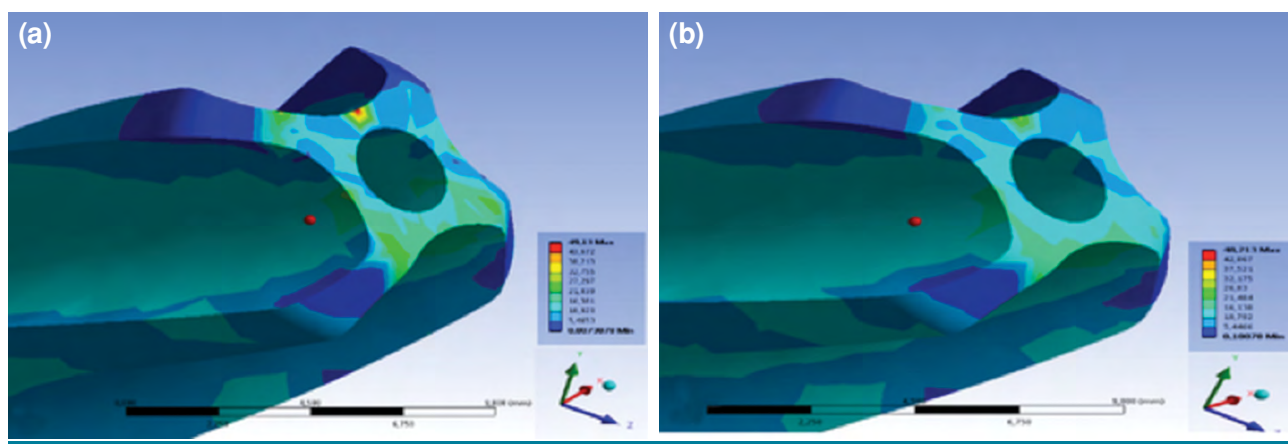

FIGURE 4. (a) Distribution of stress on tip of lag screw in classical PFNA. (b) Distribution of stress on tip of lag screw in new PFNA design.

PFNA: Proximal femoral nail antirotation.

was understood from this stress value (Figure 3c). The stress on the tip of the lag screw was found to be $49 \mathrm{mpa}$ in the standard PFNA design, while in the new design PFNA it was found as 28 mpa with a decrease of more than $40 \%$ (Figure 4 and 5).

\section{DISCUSSION}

Intramedullary nails and plate-screw systems are commonly used in the treatment of ITFFs. ${ }^{[16]}$ Intramedullary fixation is favorable due to the short operation time, minimal surgical bleeding, better stability, and allowing early postoperative loading. ${ }^{[17]}$ We have demonstrated that modifying the nail used for proximal femoral antirotation - an intramedullary fixation method - leads to increased fracture stabilization and implant resistance against varus forces. Therefore, we believe complications such as implant failure, varus collapse, and cut-out will decrease.

The risk of cut-out and varus collapse in intertrochanteric femur fractures has been reported in

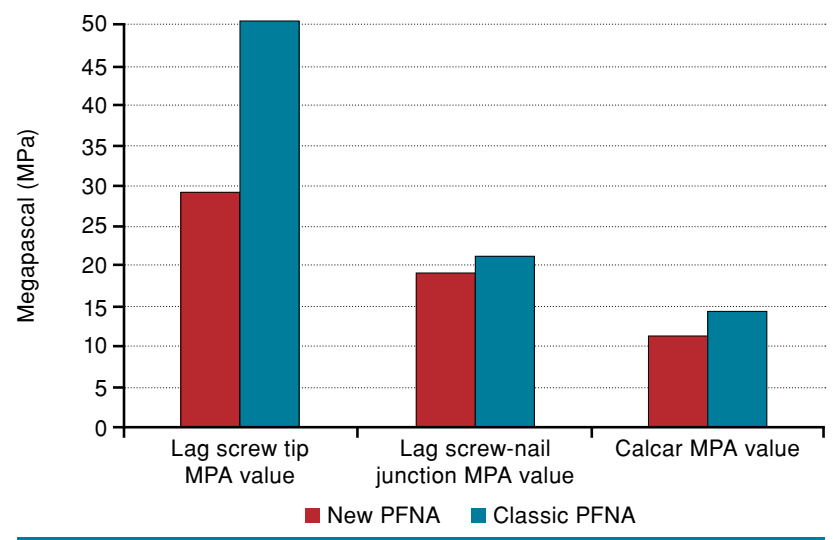

FIGURE 5. Comparison of new and classical proximal femoral nail antirotation designs in terms of stress on tip of lag screw, lag screw-nail junction, and calcar region.

PFNA: Proximal femoral nail antirotation. recently performed studies to be possibly affected by many factors such as fracture type, fracture reduction, and placement of lag screw, osteoporosis, cervical angle difference, fracture instability and varus reduction. ${ }^{[17-20]}$ Precise reduction reduces the risk of implant failure in intertrochanteric fractures. ${ }^{[21]}$ In their finite element analysis, Furui et al. ${ }^{[22]}$ have shown that varying degrees of varus and rotational deforming forces lead to significantly increased stress on the calcar region. In our study, the stress at the junction of the nail and the additional screw inserted through the greater trochanter was $42.5 \mathrm{mpa}$. We believe that this stress is caused by the fact that the additional screw inserted through the greater trochanter sustains the femoral head against varus malalignment. As a result, the stress on the calcar region has decreased by $30 \%$ compared to the classic nail design. This decrease will bring along significant decreases in varus collapse, implant failure, and cutout rates. We believe that the decreased complication rates will translate into decreased revision surgery rates. This reduced stress on the calcar region by the new PFNA design is even more significant in cases of varus fixation where complete anatomical reduction cannot be achieved.

Continuous microfracture of the bone in contact with the lag screw is one of the important reasons that cause the lag screw to change position in the femoral head. In their study, Liang et al. ${ }^{[14]}$ state that the varus tendency of the femoral head causes microfractures in the bone in contact with the tip of the lag screw. They also indicate that this varus tendency and increased microfractures lead the lag screw to pierce the femoral head and subsequently cause cut-out. The high stress on the tip of the lag screw increases the risk of microfractures and cut-out. ${ }^{[14]}$ In our study, we found that maximum stress was $28 \mathrm{mpa}$ on the tip of the lag screw in the new PFNA design compared to 
49 mpa in the classical design. This shows that the new PFNA design reduces the stress on the tip of the lag screw by approximately $50 \%$. Also, the additional screw will rest against the cortex from inside without penetrating the calcar and will thus prevent varus malalignment. Herein, it can be said that our new PFNA design is effective both in preventing varus tendency and in reducing the stress on the tip of the lag screw and the subsequent microfractures, thus significantly decreasing the possibility of varus collapse and cut-out.

The new PFNA is not significantly different in production and cost when compared to classical PFNA. Although additional screws can be adapted to many existing PFNA designs, the use of this additional screw may be optional depending on the surgeon's preference. The new PFNA design is mechanically superior and practical to apply while not increasing treatment costs significantly. It increases stability and reduces complications.

The limitation of our study is that although the new PFNA design had favorable outcomes in the computer simulation, we could not obtain clinical results. Therefore, this design must first be subjected to biomechanical tests. The subsequent outcomes can shed light on the clinical feasibility of this model. In our study, we also found that the stress in the calcar region had decreased. Further clinical studies are needed to determine whether this reduction will cause non-union of the fracture. Another limitation of the study is not having investigated any significant weakness that the passage of the additional screw, which is inserted through the greater trochanter, through the lag screw may cause. Further studies are needed to investigate the biomechanical properties of the lag screw and the additional screw.

In conclusion, our new PFNA design is superior to the classical PFNA in its mechanical properties. However, there is a need for extensive clinical and biomechanical studies on this new design.

\section{Declaration of conflicting interests}

The authors declared no conflicts of interest with respect to the authorship and/or publication of this article.

\section{Funding}

The authors received no financial support for the research and/or authorship of this article.

\section{REFERENCES}

1. Bozkurt HH, Tokgöz MA, Yapar A, Atik OŞ. What is the importance of canal-to-diaphysis ratio on osteoporosisrelated hip fractures? Eklem Hastalik Cerrahisi 2019;30:296-300.
2. Siddiqui $\mathrm{YS}$, Khan $\mathrm{AQ}$, Asif $\mathrm{N}$, Khan MJ, Sherwani MKA. Modes of failure of proximal femoral nail (PFN) in unstable trochanteric fractures. MOJ Orthop Rheumatol 2019;11:7-16.

3. Sidhu AS, Singh AP, Singh AP, Singh S. Total hip replacement as primary treatment of unstable intertrochanteric fractures in elderly patients. Int Orthop 2010;34:789-92.

4. Hassankhani EG, Omidi-Kashani F, Hajitaghi $H$, Hassankhani GG. How to Treat the Complex Unstable Intertrochanteric Fractures in Elderly Patients? DHS or Arthroplasty. Arch Bone Jt Surg 2014;2:174-9.

5. Kamboj P, Sharma PK, Jesadia B, Arora S, Siwach RC. A comparative prospective study of osteosynthesis in intertrochanteric fractures, using dynamic hip screw (DHS) and proximal femoral nailing (PFN). International Journal of Orthopaedics Sciences 2019;5:954-60.

6. Sharma A, Mahajan A, John B. A Comparison of the Clinico-Radiological Outcomes with Proximal Femoral Nail (PFN) and Proximal Femoral Nail Antirotation (PFNA) in Fixation of Unstable Intertrochanteric Fractures. J Clin Diagn Res 2017;11:RC05-RC09.

7. Mallya S, Kamath SU, Madegowda A, Krishnamurthy SL, Jain MK, Holla R. Comparison of radiological and functional outcome of unstable intertrochanteric femur fractures treated using PFN and PFNA-2 in patients with osteoporosis. Eur J Orthop Surg Traumatol 2019;29:1035-42.

8. Wang J, Ma JX, Lu B, Bai HH, Wang Y, Ma XL. Comparative finite element analysis of three implants fixing stable and unstable subtrochanteric femoral fractures: Proximal Femoral Nail Antirotation (PFNA), Proximal Femoral Locking Plate (PFLP), and Reverse Less Invasive Stabilization System (LISS). Orthop Traumatol Surg Res 2020;106:95-101.

9. Andruszkow H, Frink M, Frömke C, Matityahu A, Zeckey C, Mommsen P, et al. Tip apex distance, hip screw placement, and neck shaft angle as potential risk factors for cut-out failure of hip screws after surgical treatment of intertrochanteric fractures. Int Orthop 2012;36:2347-54.

10. Yaozeng X, Dechun G, Huilin Y, Guangming Z, Xianbin W. Comparative study of trochanteric fracture treated with the proximal femoral nail anti-rotation and the third generation of gamma nail. Injury 2010;41:1234-8.

11. Strauss E, Frank J, Lee J, Kummer FJ, Tejwani N. Helical blade versus sliding hip screw for treatment of unstable intertrochanteric hip fractures: a biomechanical evaluation. Injury 2006;37:984-9.

12. Kochai A, Uysal M, Ozalay M, Cinar BM, Battal V, Avci MC. Comparision of PFN and INTERTAN nail for unstable intertrochanteric femoral fracture in mobile patients. Int J Clin Exp Med 2019;12:5468-74.

13. Marsh JL, Slongo TF, Agel J, Broderick JS, Creevey W, DeCoster TA, et al. Fracture and dislocation classification compendium - 2007: Orthopaedic Trauma Association classification, database and outcomes committee. J Orthop Trauma 2007;21(10 Suppl):S1-133.

14. Liang $C$, Peng $R$, Jiang $N$, Xie G, Wang L, Yu B. Intertrochanteric fracture: Association between the coronal position of the lag screw and stress distribution. Asian J Surg 2018;41:241-9.

15. Li J, Yin P, Zhang L, Chen H, Tang P. Medial anatomical buttress plate in treating displaced femoral neck fracture a finite element analysis. Injury 2019;50:1895-900. 
16. Lenich A, Vester H, Nerlich M, Mayr E, Stöckle U, Füchtmeier B. Clinical comparison of the second and third generation of intramedullary devices for trochanteric fractures of the hip--Blade vs screw. Injury 2010;41:1292-6.

17. Kashigar A, Vincent A, Gunton MJ, Backstein D, Safir O, Kuzyk PR. Predictors of failure for cephalomedullary nailing of proximal femoral fractures. Bone Joint J 2014;96:1029-34.

18. Bojan AJ, Beimel C, Taglang G, Collin D, Ekholm C, Jönsson A. Critical factors in cut-out complication after Gamma Nail treatment of proximal femoral fractures. BMC Musculoskelet Disord 2013;14:1.

19. Pervez H, Parker MJ, Vowler S. Prediction of fixation failure after sliding hip screw fixation. Injury 2004;35:994-8.

20. Parker MJ. Valgus reduction of trochanteric fractures. Injury 1993;24:313-6.

21. Caruso G, Bonomo M, Valpiani G, Salvatori G, Gildone A, Lorusso $V$, et al. A six-year retrospective analysis of cut-out risk predictors in cephalomedullary nailing for pertrochanteric fractures: Can the tip-apex distance (TAD) still be considered the best parameter? Bone Joint Res 2017;6:481-8.

22. Furui A, Terada N, Mito K. Mechanical simulation study of postoperative displacement of trochanteric fractures using the finite element method. J Orthop Surg Res 2018;13:300. 